\section{Aortic homograft valve functioning for twenty-eight years in the tricuspid position}

\section{To the Editor:}

The case history of a patient with a Hancock porcine heterograft valve (Medtronic, Inc, Minneapolis, Minn) implanted 22 years ago was reported by Wisheart. ${ }^{1}$ In 1971, $\mathrm{we}^{2}$ reported the replacement of a tricuspid valve with a preserved aortic valve homograft for Ebstein's malformation. After 28 years, the patient is still alive and active with the homograft.

A 12 year-old girl was admitted to our hospital for mild exertional dyspnea and polycythemia. On June 18, 1970, she underwent tricuspid valve replacement with an aortic homograft and suture closure of the atrial septal defect. The homograft was preserved in $70 \%$ alcohol for 7 weeks and was fixed to a Shumway-Angell ring (No. 26) by 2-layer continuous sutures. The reinforced valve was anchored to the "true anulus" of the tricuspid valve with interrupted sutures so as to leave the coronary sinus above it. No diastolic pressure gradient was detected between the right atrium and the ventricle. She was discharged from the hospital with sinus rhythm and has enjoyed an active life.

The woman is now 41 years old and visited the outpatient clinic for a follow-up study after 28 years. Physical examination revealed no cyanosis and only a Levine grade $2 / 6$ diastolic murmur over the precordium. An electrocardiogram showed complete atrioventricular block with a ventricular rate of 60 beats/min. Her condition was New York Heart Association class II. Echocardiographic study revealed a well-functioning homograft without evidence of calcification (Fig 1). A diastolic pressure gradient between the right atrium and the ventricle was estimated as $5 \mathrm{~mm} \mathrm{Hg}$. A color Doppler study showed moderate tricuspid regurgitation.

Stark and associates ${ }^{3}$ reported that the longest surviving homograft conduit was 22.7 years in his series of patients with subpulmonary homograft conduits. Recently, Rizzoli and coauthors ${ }^{4}$ reported long-term results of prosthetic valve replacement in the tricuspid position, and the longest survival time was 27.8 years after insertion of a mechanical valve. However, the very long-term result of homografts in the right side of the heart is still unknown. Between 1967 and 1969, 5 patients survived the operation in our hospital with homografts in the aortic or tricuspid position. All 4 homografts in the aortic position were replaced within 9 years, 3 because of valve malfunction and 1 because of infectious endocarditis. On the other hand, the valve in the tricuspid position is still functioning, probably because of the low mechanical stress to the valve leaflets in the right side of the heart.

In conclusion, the experience with our patient for more than a quarter of a century suggests the feasibility of homograft use in the tricuspid position, even in adolescents.

Motohiro Kawauchi, MD

Masahiro Saigusa, MD

Akira Furuse, $M D^{a}$

Shinichi Takamoto, $M D$

Department of Cardiothoracic Surgery Faculty of Medicine University of Tokyo 7-3-1, Hongo, Bunkyo-ku Tokyo, 113-8655, Japan JR Tokyo General Hospital ${ }^{a}$

2-1-3, Yoyogi, Shibuya-ku Tokyo, 151-8528, Japan

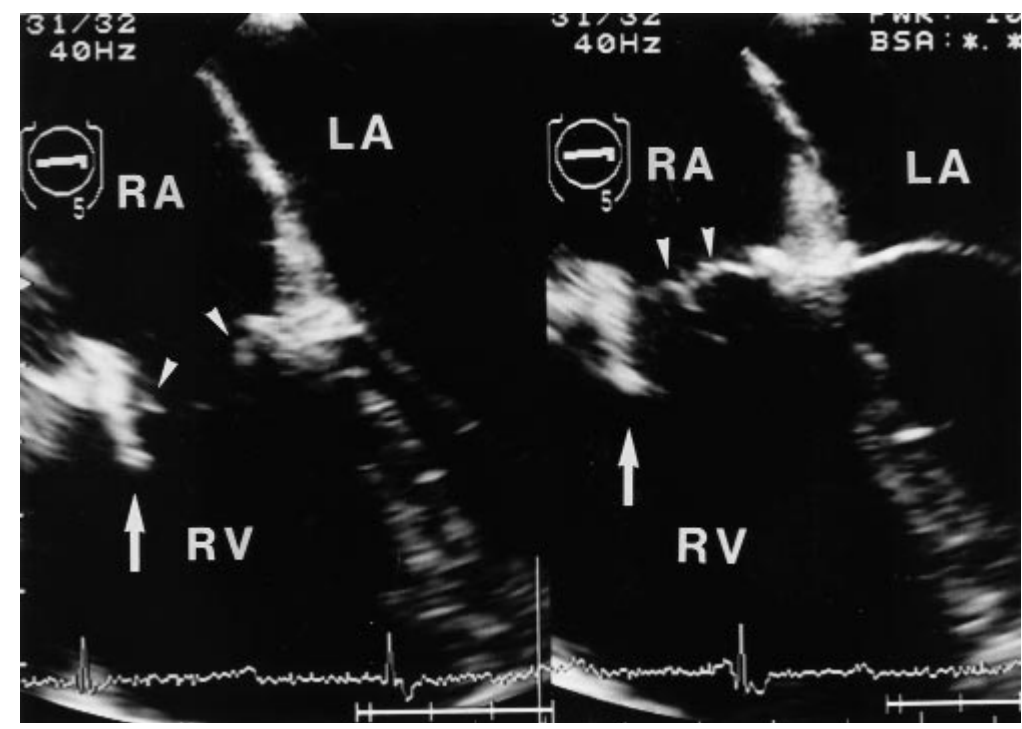

Fig 1. Transesophageal echocardiogram revealed full opening (left) and adequate closure (right) of the homograft valve. White arrows point to the Shumway-Angell ring and arrowheads point to the leaflets of the homograft. $R A$, Right atrium; $R V$, right ventricle; $L A$, left atrium. 


\section{REFERENCES}

1. Wisheart JD. Can you top this? J Thorac Cardiovasc Surg 1998; 115:267.

2. Saigusa M, Mizuno A, Ukishima H, Hasegawa T, Kobayashi H. Tricuspid valve replacement with a preserved aortic valve homograft for Ebstein's malformation: a case report. J Thorac Cardiovasc Surg 1971;62:55-8.

3. Stark J, Bull C, Stajevic M, Jothi M, Elliott M, de Leval M. Fate of subpulmonary homograft conduits: determinants of late homograft failure. J Thorac Cardiovasc Surg 1998;115:506-16.

4. Rizzoli G, De Perni P, Bottio T, Minutolog G, Thine G, Casarotto D. Prosthetic valve replacement of the tricuspid valve: biological or mechanical. Ann Thorac Surg 1998;66:S62-7.

$12 / 8 / 99093$

\section{Neurophysiologic assessment of nerve impairment in posterolateral and muscle-sparing thoracotomy}

\section{To the Editor:}

We read with great interest the recently published article by Benedetti and colleagues ${ }^{1}$ on nerve impairment in posterolateral and muscle-sparing thoracotomy. The authors reported that neurophysiologic assessment of abdominal reflexes, somatosensory-evoked potentials, and sensory thresholds to electrical stimulation of the operative scar revealed that muscle-sparing thoracotomy produced less intercostal nerve impairment than posterolateral thoracotomy.

The technical differences between the posterolateral and muscle-sparing thoracotomy should be considered ${ }^{2,3}$ :

1. The skin incision is shorter in muscle-sparing thoracotomy. 2. The latisimus dorsi muscle is transected during posterolateral thoracotomy. The trapezius muscle may be divided if wide exposure is required. The serratus anterior muscle is usually elevated and retracted anteriorly. If necessary for exposure, the serratus anterior is divided as close as possible to its origins on the ribs.

Entry into the pleural cavity through the intercostal space or through the periosteal bed of a rib and retraction of the ribs are the same for both posterolateral and muscle-sparing thoracotomies.

Intercostal nerves present at the intercostal space are mostly severed during entrance into the pleural cavity, and wide spreading of the ribs is responsible for a major component of postthoracotomy pain. ${ }^{4}$ Muscle-sparing thoracotomy avoids transection of the latisimus dorsi and the serratus anterior muscles, thereby decreasing postthoracotomy pain. ${ }^{5}$

We think that intercostal nerve impairment is not the sole contributing factor in the neurophysiologic difference between the two types of thoracotomy. The data presented by Benedetti and colleagues should also have represented that nerves innervating the chest wall muscles (eg, the thoracodorsal nerve) and nociceptors of the skin have an important contribution to postoperative pain.

Ferzat Zonüzi, MD

Mustafa Yüksel, MD

Marmara University Hospital

Department of Thoracic Surgery PK 97, 81020 Acibadem Istanbul, Turkey

\section{REFERENCES}

1. Benedetti F, Vighetti S, Ricco C, Amanzio M, Bergamasco L, Casadio C, et al. Neurophysiologic assessment of nerve impairment in posterolateral and muscle-sparing thoracotomy. J Thorac Cardiovasc Surg 1998;115:841-7.

2. Morres DWO, Foster ED, McKneally MF. Incision. In: Pearson FG, Deslauriers J, Ginsberg RJ, editors. Thoracic surgery, New York: Churchill Livingstone; 1995. p. 113-29.

3. Urschel HC, Cooper JD. Atlas of thoracic surgery. New York: Churchill Livingstone. 1995.

4. McKneally MF. Lobectomy without a rib spreader (editorial). Ann Thorac Surg 1992;54:2.

5. Sadighi PJ, Woodworth CS. Muscle-splitting thoracotomy. Am Surg 1998;64:370-1.

[Response declined]

12/8/99096 